\title{
Susceptibility variation of Malassezia pachydermatis to antifungal agents according to isolate source
}

\author{
Caroline Borges Weiler ${ }^{1}$, Francielli Pantella Kunz de Jesus ${ }^{2}$, Graziela Habib Nardi ${ }^{3}$, \\ Érico Silva Loreto ${ }^{2}$, Janio Morais Santurio ${ }^{2}$, Selene Dall'Acqua Coutinho ${ }^{3}$, \\ Sydney Hartz Alves ${ }^{1,2}$ \\ ${ }^{1}$ Programa de Pós-graduação em Ciências Farmacêuticas, Universidade Federal de Santa Maria, \\ Santa Maria, RS, Brasil. \\ ${ }^{2}$ Departamento de Microbiologia e Parasitologia, Universidade Federal de Santa Maria, \\ Santa Maria, RS, Brasil. \\ ${ }^{3}$ Laboratório de Biologia Molecular e Celular, Universidade Paulista, São Paulo, SP, Brasil.
}

Submitted: August 18, 2011; Approved: July 02, 2012.

\begin{abstract}
Malassezia pachydermatis is associated with dermatomycoses and otomycosis in dogs and cats. This study compared the susceptibility of $M$. pachydermatis isolates from sick (G1) and healthy (G2) animals to azole and polyene antifungals using the M27-A3 protocol. Isolates from $\mathrm{G} 1$ animals were less sensitive to amphotericin B, nystatin, fluconazole, clotrimazole and miconazole.
\end{abstract}

Key words: Malassezia pachydermatis, susceptibility, antifungal agents.

Currently, the genus Malassezia includes fourteen species, thirteen of which are lipid-dependent and are most frequently recovered from humans, ruminants and horses (Malassezia furfur, M. globosa, M. obtusa, M. restricta, M.slooffiae, M. sympodialis, M. dermatis, M. nana, M. japonica, M. yamatoensis, M. equina, M. caprae and M. cuniculi); the non-lipid-dependent species, $M$. pachydermatis, is commonly recovered from dogs and cats (Cabañes et al., 2011). The distribution of different species, the colonization prevalence and the population density of Malassezia spp. varies by carrier and affected sites of the body, which are influenced by the skin lipid composition and the presence of competitive microbiota (Sugita et al., 2010).

M. pachydermatis is the species most adapted to animals and is often recovered as part of the microbiota of the ear canal and skin of dogs, cats and other species of domestic and wild animals. In dogs and cats, M. pachydermatis has been linked to both localized (otitis externa and dermatitis) and systemic disease (Guillot and Bond, 1999). Antifungal triazoles are commonly used for treatment, and treatment should be continued until the clinical signs re- solve and yeast are no longer observed during direct examination (Daigle, 2007).

The aim of this study was to compare the susceptibility of $M$. pachydermatis isolates recovered from healthy animals and animals with otitis to ketoconazole, fluconazole, itraconazole, voriconazole, clotrimazole, miconazole, nystatin and amphotericin B.

We studied two groups of M. pachydermatis isolates taken from dogs and cats at the Cellular and Molecular Biology Laboratory of the Paulista University (UNIP, São Paulo, Brazil). Group 1 (G1) was comprised of 40 isolates recovered from the ear canals of animals with otitis externa; group 2 (G2) was comprised of 40 isolates recovered from the ear canals of healthy animals. Isolate identification was confirmed by randomly amplified polymorphic DNA using the Mpa-F (CTGCCATACGGATGCGCAAG) and 58S-R (TTCGCTGCGTTCTTCATCGA) primers (Sugita et al., 2003).

Stock solutions of antifungal agents were obtained from the dilution of each antifungal drug in dimethyl sulfoxide or sterile distilled water for fluconazole. The drugs were serially diluted in RPMI 1640 broth $\left(\mathrm{GIBCO}^{\mathrm{TM}}\right)$ to obtain the following final concentrations: ketoconazole 
(16 $\mu \mathrm{g} / \mathrm{mL}-0.007 \mu \mathrm{g} / \mathrm{mL}$ ) (Janssen Beerse), itraconazole (16 $\mu \mathrm{g} / \mathrm{mL}-0.007 \mu \mathrm{g} / \mathrm{mL}$ ) (Janssen Beerse), clotrimazole (64 $\mu \mathrm{g} / \mathrm{mL}-0.125 \mu \mathrm{g} / \mathrm{mL})$ (Bayer), voriconazole $(16 \mu \mathrm{g} / \mathrm{mL}$ $0.007 \mu \mathrm{g} / \mathrm{mL}) \quad$ (Pfizer), miconazole $(64 \mu \mathrm{g} / \mathrm{mL}$ $0.125 \mu \mathrm{g} / \mathrm{mL}) \quad$ (Labware), nystatin (64 $\mu \mathrm{g} / \mathrm{mL}-$ $0.125 \mu \mathrm{g} / \mathrm{mL})$ (Bristol-Myers), amphotericin B $(16 \mu \mathrm{g} / \mathrm{mL}-$ $0.007 \mu \mathrm{g} / \mathrm{mL}$ ) (Bristol-Myers) and fluconazole (64 $\mu \mathrm{g} / \mathrm{mL}-0.125 \mu \mathrm{g} / \mathrm{mL}$ ) (Pfizer). Inocula were obtained from 48-h pure Dixon agar cultures and consisted of microorganism suspensions in sterile saline $(0.85 \%)$ plus Triton $\mathrm{X}-100(0.05 \%)$ (Merck), whose turbidity was adjusted to 0.5 on the McFarland scale. Inocula were diluted 1:50 in sterile distilled water and then at 1:20 in RPMI 1640 broth. For each isolate, microdilution plates containing $10 \mu$ Lof antifungals in RPMI 1640 diluted in different concentrations were inoculated with $10 \mu$ Lof the standardized inocula. As positive control, the standardized inocula were cultured alone; the negative control was the antifungal alone diluted in RPMI 1640 broth. Culture plates were incubated at $37^{\circ} \mathrm{C}$ for $48 \mathrm{~h}$. Minimum inhibitory concentrations (MICs) were recorded following the M27-A3 protocol (CLSI, 2007). All tests were performed in duplicate. The Mann-Whitney test was used to compare the two groups of isolates to determine whether they had similar susceptibility patterns to the antifungal agents tested.

Because no standardized susceptibility testing procedures exist for $M$. pachydermatis, the present study was based on the M27-A3 protocol (CLSI, 2007); in the absence of specific breakpoints for Malassezia spp., we utilized breakpoints described for Candida spp.

In this work, the lowest MICs were observed with ketoconazole, itraconazole and voriconazole (Table 1). Voriconazole showed the smallest variations of MICs with the MICs for G1 isolates ranging from $0.01-0.25 \mu \mathrm{g} / \mathrm{mL}$, while the MICs for G2 isolates ranged from 0.01 to $0.125 \mu \mathrm{g} / \mathrm{mL}$. These data are consistent with findings from Gupta et al. (2000) that reported MICs ranging from 0.03 to $0.25 \mu \mathrm{g} / \mathrm{mL}$. Hammer et al. (2000) reported the lowest MICs with ketoconazole, with $\mathrm{MIC}_{50}$ and $\mathrm{MIC}_{90}$ values similar to values we recorded for G2 isolates (Table 2). Although the susceptibility testing for itraconazole, fluconazole and amphotericin B showed that $100 \%$ of the isolates were susceptible to these antifungals, the MIC range was higher in $\mathrm{G} 1$ isolates compared to $\mathrm{G} 2$ isolates (Table 2). Nakamura et al. (2000) tested seven Malassezia species and all were susceptible to itraconazole; however, M. pachydermatis exhibited the highest MIC range among the species evaluated.

Statistical analysis revealed significant differences in susceptibility between G1 and G2 isolates. In the susceptibility tests with amphotericin B, nystatin, fluconazole, miconazole and clotrimazole, G1 isolates had significantly higher MICs compared to G2 isolates $(p<0.05)$. The existence of a different susceptibility profile between the two groups revealed higher antifungal resistance in the isolates obtained from infected animals (G1). The study by

Table 1 - Distribution of MICs ( $\mu \mathrm{g} / \mathrm{mL})$ for $M$. pachydermatis isolated from ear canals of animals with and without otitis.

\begin{tabular}{|c|c|c|c|c|c|c|c|c|c|}
\hline & \multirow[t]{2}{*}{ Groups } & \multicolumn{8}{|c|}{ No. $(\%)$ of isolates sensitive to concentrations of: } \\
\hline & & 0.01 & 0.03 & 0.06 & 0.125 & 0.25 & 0.5 & 1.0 & 2.0 \\
\hline \multirow[t]{2}{*}{$\mathrm{KTZ}^{\mathrm{a}}$} & G1 & $19(47.5)$ & - & $3(7.5)$ & $8(20)$ & $2(5)$ & $8(20)$ & - & - \\
\hline & G2 & $17(42.5)$ & $2(5)$ & $5(12.5)$ & $10(25)$ & $4(10)$ & $2(5)$ & - & - \\
\hline \multirow[t]{2}{*}{$\mathrm{FLZ}^{\mathrm{b}}$} & G1 & $2(5)$ & $2(5)$ & $3(7.5)$ & $9(22.5)$ & $5(12.5)$ & $15(37.5)$ & $4(10)$ & - \\
\hline & G2 & $3(7.5)$ & $2(5)$ & $2(5)$ & $11(27.5)$ & $5(12.5)$ & $7(17.5)$ & - & - \\
\hline \multirow[t]{2}{*}{$\mathrm{ITZ}^{\mathrm{c}}$} & G1 & $22(55)$ & $2(5)$ & $4(10)$ & $5(12.5)$ & $3(7.5)$ & $4(10)$ & - & - \\
\hline & G2 & $17(42.5)$ & $3(7.5)$ & $10(25)$ & $9(22.5)$ & $1(2.5)$ & - & - & - \\
\hline \multirow[t]{2}{*}{$\mathrm{VRZ}^{\mathrm{d}}$} & G1 & $10(25)$ & $10(25)$ & $9(22.5)$ & $7(17.5)$ & $4(10)$ & - & - & - \\
\hline & G2 & $16(40)$ & $9(22.5)$ & $6(15)$ & $9(22.5)$ & - & - & - & - \\
\hline \multirow[t]{2}{*}{$\mathrm{CTZ}^{\mathrm{e}}$} & G1 & $5(12.5)$ & $4(10)$ & $1(2.5)$ & $7(17.5)$ & $7(17.5)$ & $12(30)$ & $4(10)$ & - \\
\hline & G2 & $6(15)$ & $11(27.5)$ & $4(10)$ & $9(22.5)$ & $5(12.5)$ & $5(12.5)$ & - & - \\
\hline \multirow[t]{2}{*}{$\mathrm{MCZ}^{\mathrm{f}}$} & G1 & $6(15)$ & $6(15)$ & $2(5)$ & $4(10)$ & $8(20)$ & $14(35)$ & - & - \\
\hline & $\mathrm{G} 2$ & $9(22.5)$ & $10(25)$ & $5(12.5)$ & $5(12.5)$ & $4(10)$ & $7(17.5)$ & - & - \\
\hline \multirow[t]{2}{*}{$\mathrm{NYS}^{\mathrm{g}}$} & G1 & $3(7.5)$ & $6(15)$ & $3(7.5)$ & $5(12.5)$ & $7(17.5)$ & $11(27.5)$ & $1(2.5)$ & $4(10)$ \\
\hline & G2 & $7(17.5)$ & $8(20)$ & $5(12.5)$ & $6(15)$ & $5(12.5)$ & $7(17.5)$ & $2(5)$ & - \\
\hline \multirow[t]{2}{*}{$\mathrm{AMB}^{\mathrm{h}}$} & G1 & $4(10)$ & $4(10)$ & $1(2.5)$ & $7(17.5)$ & $7(17.5)$ & $13(32.5)$ & $4(10)$ & - \\
\hline & G2 & $12(30)$ & $3(7.5)$ & $2(5)$ & $8(20)$ & $3(7.5)$ & $12(30)$ & - & - \\
\hline
\end{tabular}

${ }^{\mathrm{a}}$ Ketoconazole, ${ }^{\mathrm{b}}$ Fluconazole, ${ }^{\mathrm{c}}$ Itraconazole, ${ }^{\mathrm{d}}$ Voriconazole, ${ }^{\mathrm{e}}$ Clotrimazole, ${ }^{\mathrm{f}}$ Miconazole, ${ }^{\mathrm{g}}$ Nystatin, ${ }^{\mathrm{h}}$ Amphotericin B. G1: isolated from animals with otitis; G2: saprophytic isolates. 
Table 2 - In vitro susceptibility of M. pachydermatis isolates to antifungal agents.

\begin{tabular}{lccccc}
\hline Antifungal & Groups & $\mathrm{MIC} \mathrm{range}^{\mathrm{a}}(\mu \mathrm{g} / \mathrm{mL})$ & $\mathrm{MIC}_{50}{ }^{\mathrm{b}}(\mu \mathrm{g} / \mathrm{mL})$ & $\mathrm{MIC}_{90}{ }^{\mathrm{c}}(\mu \mathrm{g} / \mathrm{mL})$ & $\mathrm{GM}^{\mathrm{d}}(\mu \mathrm{g} / \mathrm{mL})$ \\
\hline Ketoconazole & $\mathrm{G} 1$ & $0.01-0.5$ & 0.06 & 0.5 & 0.048 \\
& $\mathrm{G} 2$ & $0.01-0.5$ & 0.06 & 0.25 & 0.041 \\
\hline Fluconazole & $\mathrm{G} 1^{*}$ & $0.01-1.0$ & 0.25 & 0.5 & 0.219 \\
& $\mathrm{G} 2^{* *}$ & $0.01-0.5$ & 0.125 & 0.5 & 0.068 \\
\hline Itraconazole & $\mathrm{G} 1$ & $0.01-0.5$ & 0.01 & 0.25 & 0.032 \\
& $\mathrm{G} 2$ & $0.01-0.25$ & 0.03 & 0.125 & 0.032 \\
\hline Voriconazole & $\mathrm{G} 1$ & $0.01-0.25$ & 0.03 & 0.125 & 0.042 \\
& $\mathrm{G} 2$ & $0.01-0.125$ & 0.03 & 0.125 & 0.029 \\
\hline Clotrimazole & $\mathrm{G}{ }^{*}$ & $0.01-1.0$ & 0.25 & 0.5 & 0.163 \\
& $\mathrm{G} 2^{* *}$ & $0.01-0.5$ & 0.06 & 0.5 & 0.069 \\
\hline Miconazole & $\mathrm{G}{ }^{*}$ & $0.01-0.5$ & 0.25 & 0.5 & 0.124 \\
\hline Nystatin & $\mathrm{G} 2^{* *}$ & $0.01-0.5$ & 0.06 & 0.5 & 0.061 \\
\hline Amphotericin B & $\mathrm{G}{ }^{*}$ & $0.01-2.0$ & 0.25 & 1.0 & 0.181 \\
& $\mathrm{G} 2^{* *}$ & $0.01-1.0$ & 0.06 & 0.5 & 0.084 \\
\hline
\end{tabular}

G1: isolated from animals with otitis; G2: saprophytic isolates; ${ }^{a}$ Interval between the lowest and highest MICs; ${ }^{b}$ Minimum concentration of the antifungal agent able to inhibit the growth of $50 \%$ of the isolates; ${ }^{\mathrm{c}}$ Minimum concentration of the antifungal agent able to inhibit the growth of $90 \%$ of the isolates; ${ }^{\mathrm{d}}$ Geometric mean of MICs. $(*)(* *)$ Statistically different susceptibility profiles $(\mathrm{p}<0.05)$.

Lyskova et al. (2007) using M. pachydermatis isolates from animals with and without otitis media found that all isolates exhibited high susceptibility to all of the antifungal agents tested in this study, except for fluconazole, to which $4.4 \%$ of the isolates were resistant. However, in this same study, significant differences in susceptibility between the two isolate groups were not observed. Fluconazole resistance has been described previously as Eichenberg et al. (2003) observed fluconazole resistance in $2.4 \%$ of the 82 isolates tested. Further, Jesus et al. (2011) induced resistance to fluconazole in vitro, demonstrating that $M$. pachydermatis isolates can become resistant during treatment with this antifungal. Bernardo et al. (1998) found a $M$. pachydermatis isolate that was resistant to several antifungals, including amphotericin $\mathrm{B}$, nystatin and miconazole.

Malassezia species have a structure resembling a capsule around the cell wall that provides protection and is similar in form to the capsule of Cryptococcus spp. (Ashbee and Bond, 2010). In saprophytic strains, this capsule contains high levels of lipids, blocking the exposure of fungal antigenic proteins. Factors such as humidity, high temperature and high fat environment favor rapid $M$. pachydermatis multiplication, which is accompanied by decreased lipid content and exposure of antigenic particles. The reduced susceptibility observed in G1 isolates against azole antifungal agents might be linked to variations in lipid composition. The main mechanism of action of azoles is to inhibit ergosterol synthesis. However, these drugs also act on the cell membrane through direct interaction with its lipid components (Hitchcock et al., 1986). Thus, during infection, the body's immune cells release substances that promote a lipid imbalance in the constitution of the fungal membrane, affecting membrane permeability (De Kruyff $e t$ al., 1973) and interfering with the action of azole antifungal agents. In the case of polyene antifungal agents, the reduced susceptibility of the G1 isolates may be related to the high activity of fungal intracellular enzymes such as catalase and/or superoxide dismutase. In microorganisms, catalase plays an important role in the detoxification of reactive oxygen species that are released by phagocytic cells during the host immune response (Hampton et al., 1998). Because polyenes act directly on fungal ergosterol causing direct oxidative damage to the cell membrane, the high concentration of catalase in fungal cells could protect the fungal cells from the oxidative action of polyene antifungal agents, possibly explaining the higher MICs in isolates obtained from animals with malasseziosis.

This study demonstrated that M. pachydermatis isolated from animals with otitis are less sensitive to some antifungal agents than yeasts isolated from animals without otitis. This finding may explain because some malasseziosis treatment failure and emphasizes the importance to evaluate the susceptibility of this pathogenic fungi.

\section{References}

Ashbee HR, Bond R (2010) Malassezia Species and Immunity: Host-Pathogen Interactions. In: Boekhout T, GuéhoKellermann E, Mayser P, Velegraki A (eds) Malassezia and 
the Skin - Science and Clincial Practice. Springer, New York, pp 144-146.

Bernardo FM, Martins HM, Martins ML (1998) A survey of mycotic otitis externa of dogs in Lisbon. Rev Iberoam Micol 15:163-165.

Cabañes FJ, Veja S, Castellá G (2011) Malassezia cuniculi sp. nov., a novel yeast species isolated from rabbit skin. Med Mycol 49:40-48.

Clinical and Laboratory Standards Institute (2007) Reference Method for Broth Diluition Antifungal Susceptibility Testing of Yeast: Approved Guideline M27-A3, v. 28.CLSI, Wayne, PA,USA, 1-25.

Daigle JC (2007) Clinical clues, diagnosis and treatment of Malassezia dermatitis. The North American Veterinary Conference Congress, Orlando, Flórida, 21, pp 317-318.

De Kruyff B, De Greef WJ, Eyk RVW, Demel RA, Van Deenen LLM (1973) The effect of different fatty acid and sterol composition on the erythritol flux through the cell membrane of Acholeplasma laidlawii. Biochimica et Biophysica Acta (BBA) - Biomembranes 298:479-499.

Eichenberg ML, Appelt CE, Berg V, Muschner AC, Nobre MO, Matta D, Alves SH, Ferreiro L (2003) Susceptibility of Malassezia pachydermatis to azole antifungal agents evaluated by a new broth microdilution method. Acta Sci Vet 31:75-80

Guillot J, Bond R (1999) Malassezia pachydermatis: A review. Med Mycol 37:295-306.

Gupta AK, Kohli Y, Li A, Summerbell RC (2000) In vitro susceptibility of the seven Malassezia species to ketoconazole, voriconazole, itraconazole e terbinafina. Brit J Dermatol 142:758-765.

Hammer KA, Carson CF, Riley TV (2000) In vitro activities of ketoconazole, econazole, miconazole and Melaleuca alternifolia (tea tree) oil against Malassezia species. Antimicrob Agents Ch 44:467-469.

Hampton MB, Kettle AJ, Winterbourn CC (1998) Inside the neutrophil phagosome: Oxidants, myeloperoxidase and bacterial killing. Blood 92:3007-3017.

Hitchcock C, Barrett-Bee K, Russel N (1986) The lipid composition of azoles-sensitive and azole-resistant strains of Candida albicans. J Gen Microbiol 132:2421-2431.

Jesus FPK, Lautert C, Zanette RA, Mahl DL, Azevedo MI, Machado MLS, Alves SH, Botton SA, Dutra V, Santurio JM (2011) In vitro susceptibiliy of fluconazole-susceptible and -resistent isolates of Malassezia pachydermatis against azoles. Vet Microbiol 152:161-164.

Lyskova P, Vydrzalova M, Mazurova J (2007) Identification and antimicrobial susceptibility of bacteria and yeasts isolated from healthy dogs and dogs with otitis externa. J Vet Med A 54:559-563.

Nakamura Y, Kano R, Murai T, Watanabe S, Hasegawa A (2000) Susceptibility testing of Malassezia species using the urea broth microdilution method. Antimicrob Agents $\mathrm{Ch}$ 44:2185-2186.

Sugita T, Boekhout T, Velegraki A, Guillot J, Hadina S, Cabañes J (2010) Epidemiology of Malassezia - Related skin diseases. In: Boekhout T, Guého E, Mayser P, Velegraki A (eds) Malassezia and the Skin: Science and Clinical Practice. Springer, New York, pp 65-120.

Sugita T, Taqkashima M, Kodama M, Tsubol R, Nishikawa A (2003) Description of a new yeast species, Malassezia japonica, abd its detection in patients with atopic dermatitis and healthy subjects. J Clin Microbiol 41:4695-4699.

All the content of the journal, except where otherwise noted, is licensed under a Creative Commons License CC BY-NC. 